\title{
Yaws in Ecuador: impact of control measures on the disease in the Province of Esmeraldas
}

\author{
M Anselmi, E Araujo, A Narváez, P J Cooper, R H Guderian
}

\begin{abstract}
Objectives-To determine the impact of a community-based programme of yaws control in Esmeraldas province in Ecuador.

Methods-Community health workers provided mass treatment and subsequent surveillance for the detection and treatment of new cases and their contacts over the period 1988 to 1993 . Clinical and serological surveys were performed in the study area in 1988 and 1993.

Results-Over the 5 year observation period, the number of communities with active infections had decreased by $75 \%$, from 20 communities in 1988 to 5 in 1993. In 1993, 4 communities were found free of clinical infections as well as latent infections. There was a corresponding decrease of $94.6 \%$ in the prevalence of dermal lesions (from $11.2 \%$ to $0.6 \%$ ), and a reduction of $97.3 \%$ in latent infections (from $93 \cdot 6 \%$ to $2 \cdot 5 \%$ ).

Conclusions-The control of yaws using existing community-based health workers has proved very effective in Ecuador.
\end{abstract}

(Genitourin Med 1995;71:343-346)

Keywords: Yaws; Ecuador; Primary health care

\section{Introduction}

In Ecuador, since 1940, active clinical cases of yaws have been documented in the northwestern part of the coastal province of Esmeraldas $^{1}$ and in the areas of Cotuno and Archidona in the eastern Amazon province of Napo. ${ }^{23}$ In 1958 a national eradication programme was initiated using mass penicillin treatment. An established surveillance programme continued until 1964 when the incidence of disease was 0.03 per 1000 population. ${ }^{4}$ Since 1964 , although a steady increase of disease has been documented in the province of Esmeraldas, ${ }^{56}$ no cases have been documented in the Napo province. In 1988, an epidemiological survey in the Santiago Basin, province of Esmeraldas, showed a prevalence of $11.3 \%$ for active disease and a seropositivity of $94.9 \% .^{7}$ The Río Santiago was hyperendemic (prevalence, $17 \cdot 9 \%$; seropositivity, $98.0 \%$ ) while Río Zapallito was mesoendemic, and Río Cayapas and Río Onzoles were hypoendemic for the disease. Mass treatment of the basin using benzathine penicillin $G$ was according to WHO recommendations. ${ }^{8}$ Over the past 5 years a control surveillance programme, utilising community-based primary health care workers, was employed in the detection and treatment of all new clinical cases and their contacts. To evaluate the impact of these interventions on the disease, a second epidemiological evaluation of the focus was done in 1993. Reported here are the results of this study.

\section{Materials and methods}

In the months of January to May, 1993, a second epidemiological, clinical and serological evaluation was done in the focus of yaws located in the Santiago basin, province of Esmeraldas. ${ }^{7}$ The study evaluated the same 87 communities examined in 1988 . The maximum number of those that were included in the previous study were re-examined as well as all children born after 1988. A total of 2633 persons, $94.3 \%$ of the total population according to the current census, were examined.

The epidemiological study, utilising an updated census as the basis to identify all new and previously studied individuals, was done to document all persons who presented with any of the various dermatological lesions of yaws. ${ }^{8}$ In the same special chart prepared for the first study, were noted all the clinical classification of the lesions, anatomical sites, age, sex, and race of those examined. The levels of endemicity, as defined by WHO, were used to assess the population studied. ${ }^{8}$ Hyperendemic, mesoendemic and hypoendemic areas were defined as areas in which the prevalence of active clinical lesions seen were $>10 \%$, $5-10 \%,<5 \%$ respectively.

Serological testing to detect latent cases was done on all individuals, except those less than one year of age, using the rapid plasma reagin (RPR) card test. ${ }^{9}$ All patients positive for RPR were confirmed with the FTA-Abs test. Latency was defined as the presence of a positive RPR test confirmed by FTA-Abs in the absence of evidence of any clinical lesions characteristic of yaws, without a history of other treponemal infection or post-treatment of yaws.

Seropositive individuals were treated with benzathine penicillin $\mathrm{G}$ (BPG) according to WHO recommendations. ${ }^{10}$

\section{Results}

Endemic areas

To evaluate the impact of the control programme, the 20 communities along Río 
Comparison of the prevalence of clinical cases and seropositivity by RPR and FTA-Abs in 1988 and 1993 of the 20 communities in the endemic area for yaws, Esmeraldas province, Ecuador

\begin{tabular}{|c|c|c|c|c|}
\hline \multirow[b]{2}{*}{$\begin{array}{l}\text { Geographical } \\
\text { areas }\end{array}$} & \multicolumn{4}{|c|}{ Prevalence (\%) } \\
\hline & $\begin{array}{l}\text { Clinical cases } \\
1988\end{array}$ & 1993 & $\begin{array}{l}\text { Serology } \\
1988\end{array}$ & 1993 \\
\hline \multicolumn{5}{|l|}{ Río Santiago } \\
\hline Playa de Oro & $10 \cdot 0$ & 0.0 & $98 \cdot 3$ & $2 \cdot 0$ \\
\hline Angostura & $20 \cdot 0$ & $0 \cdot 0$ & $96 \cdot 6$ & $12 \cdot 5$ \\
\hline Playa Tigre & $19 \cdot 3$ & $2 \cdot 9$ & $98 \cdot 1$ & $10 \cdot 9$ \\
\hline Palma Real & $21 \cdot 1$ & $12 \cdot 0$ & $96 \cdot 3$ & $20 \cdot 7$ \\
\hline Chanazal & $15 \cdot 2$ & 0.0 & $98 \cdot 1$ & 0.0 \\
\hline Selva Alegre & $23 \cdot 0$ & 0.0 & $99 \cdot 7$ & 0.0 \\
\hline Timbiré & $12 \cdot 6$ & 0.0 & $98 \cdot 4$ & $0 \cdot 8$ \\
\hline El Porvenir & $22 \cdot 2$ & 1.9 & $97 \cdot 6$ & $2 \cdot 4$ \\
\hline Las Antonias & $13 \cdot 0$ & $1 \cdot 4$ & $98 \cdot 3$ & $3 \cdot 8$ \\
\hline Negrital & $19 \cdot 8$ & 0.0 & $98 \cdot 7$ & $0 \cdot 0$ \\
\hline La Peña & $15 \cdot 3$ & 0.0 & $97 \cdot 1$ & $2 \cdot 6$ \\
\hline Rocafuerte & $26 \cdot 7$ & 0.0 & $97 \cdot 6$ & $2 \cdot 2$ \\
\hline \multicolumn{5}{|l|}{ Río Cayapas } \\
\hline San Miguel & $19 \cdot 0$ & 0.0 & $95 \cdot 2$ & $0 \cdot 0$ \\
\hline Mafua & $2 \cdot 0$ & 0.0 & $81 \cdot 6$ & $0 \cdot 0$ \\
\hline Zapallo Grande & $4 \cdot 0$ & 0.0 & $82 \cdot 2$ & $0 \cdot 0$ \\
\hline Telembí & $3 \cdot 5$ & $0 \cdot 0$ & $87 \cdot 2$ & $1 \cdot 4$ \\
\hline \multicolumn{5}{|l|}{ Río Zapallito } \\
\hline Juan Montalvo & $8 \cdot 9$ & 0.0 & $93 \cdot 1$ & $16 \cdot 7$ \\
\hline Aqui Me Quedo & $6 \cdot 8$ & $1 \cdot 4$ & 90.4 & $14 \cdot 3$ \\
\hline \multicolumn{5}{|l|}{ Río Onzoles } \\
\hline Colón & $2 \cdot 0$ & 0.0 & $97 \cdot 1$ & $1 \cdot 2$ \\
\hline Santo Domingo & 1.4 & 0.0 & $95 \cdot 3$ & $2 \cdot 4$ \\
\hline
\end{tabular}
Figure 1 Dermalised over all body parts in an Afroecuadorian, province of Esmeraldas, Ecuador.
Santiago, Río Cayapas, Río Zapallito and Río Onzoles, which were positive for yaws in 1988, were re-examined. Fourteen of the 20 communities were found to be positive for yaws owing to the presence of individuals with either clinical dermal lesions or latent infections. Of the 2633 persons examined, only 16 $(0 \cdot 6 \%)$ presented with clinical dermal lesions, and $60(2.5 \%)$ were detected by serology to have latent infections, as compared with a prevalence of clinical lesions of $11 \cdot 2 \%$ and a latent infection of $93.6 \%$ in 1988 . The 16 individuals with active clinical lesions of yaws

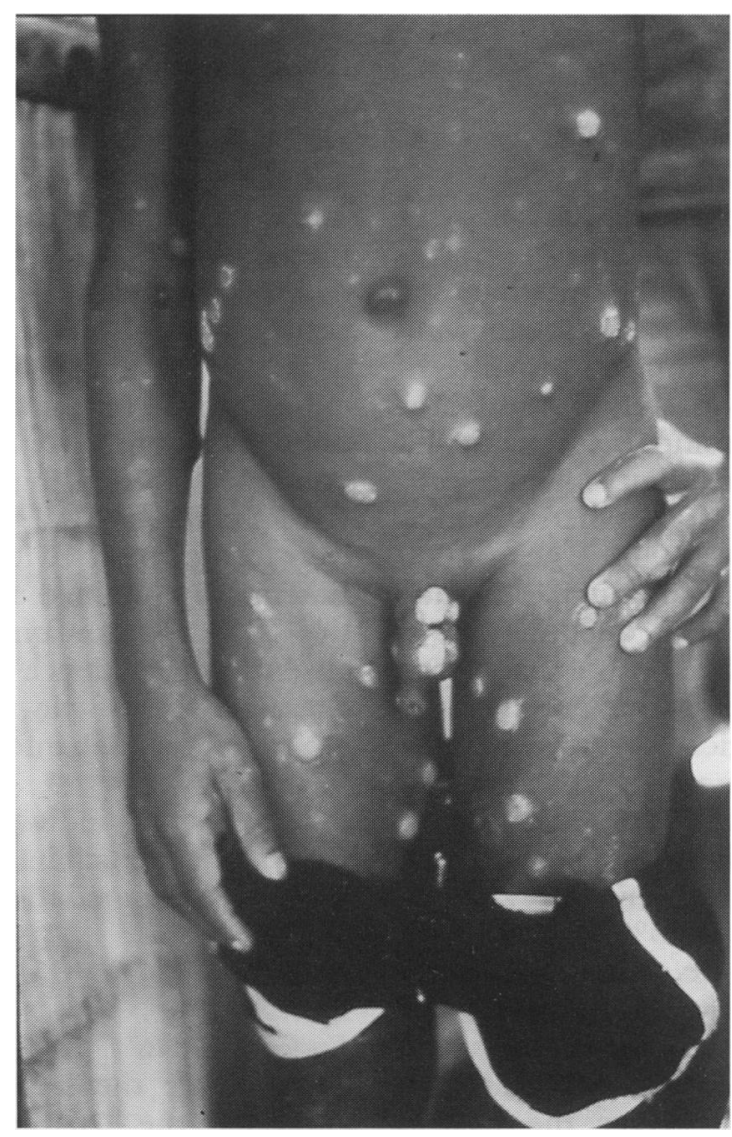

were found in only four communities located on river Río Santiago, and one on Río Zapallito as compared with the 333 persons with dermal lesions found in all 20 communities in 1988. Latent infections were found in the remaining nine communities in the threes river systems. In four communities no dermaB lesions or latent infections were detected.

Non-endemic areas

All the 67 communities that were tested in 1988 and found to be negative for yaws, stili remained negative for clinical dermal lesions? or latent infection for yaws in 1993.

\section{Prevalence}

A marked reduction in the prevalence of individuals with dermal lesions was documented in all 20 communities re-examined (table), $\vec{\circ}$ with 15 communities now free of clinical yaws as compared with 1988. A persistent focus remains active on the Río Santiago, involving three adjacent communities, Palma Real, Playa Tigre and Angostura, as documented byo the significant number of individuals with clin- $\omega$ ical lesions and latent infections. The Rio Cayapas and Rio Onzoles were found free of any clinical dermal lesions of yaws, although ao

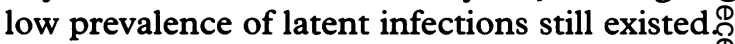
Those with latent infections and clinical pre- $-\frac{\pi}{3}$ sentation of yaws on the Río Zapallito reflectso the constant migration and personal contact that these two communities have with thes focus on Río Santiago.

The reduction in the prevalence of thoseo with latent infections in all communities reflects the efficacy of the mass treatment with penicillin in 1988 and the surveillance pro-疋 gramme of community-based detection and treatment of new cases. Those positive for RPR serology were reconfirmed as positive with FTA-Abs test.

In individuals found with dermal lesions of yaws, the majority $(93.8 \%)$ were less than $20_{5}^{\circ}$ years of age (aged 1-12 years; $62.5 \%$; aged $13-19,31 \cdot 3 \%)$. Only one case $(6 \cdot 2 \%)$ waş found in an individual over 20 years of age ( 36 years old). The clinical lesions were more fre-윽 quent in males $(82 \cdot 3 \%)$ than females $(17 \cdot 7 \%)$ D

\section{Clinical manifestation}

Single or multiple lesions were found most fre quently in the lower limbs (35\%), followed by the feet $(12 \%)$, and abdomen/lumbar area $(12 \%)$. Dermal lesions generalised over alk body parts were found in $41 \%$ of cases (fig 1 ).

The primary lesion, the papilloma both $\sin \frac{\infty}{4}$ gle and multiple, was the most common lesiono found $(82.6 \%)$ followed by the ulcerative form (17.4\%) (fig 2).

\section{Treatment}

Mass treatment with benzathine penicillin was given to the two communities on Río Zapallitos and the three communities, Palma Real, Plays Tigre and Angostura on the Río Santiago. In all other communities only the clinical and latent cases of yaws were given treatment.

In the community Palma Real on the Río Santiago during the 5 year surveillance, three 
Figure 2 Ulcerative form of yaws in the lower extremity of an

Afro-ecuadorian, province of Esmeraldas, Ecuador.

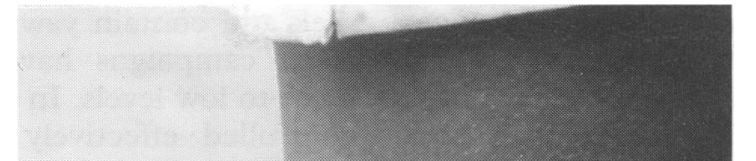

Nevertheless, a small endemic focus still persists on the Rio Santiago. This is probably due to clinical resistance to repeated penicillin treatment documented in several cases. With the constant interchange between the adjacent communities, re-infection probably occurred as witnessed by the level of latent and clinical cases found in this study. Constant surveillance of this focus is required to monitor the efficacy of the alternative treatment given and to assure that the disease is controlled. Otherwise, new periodic episodes of infection will continue to occur.

The finding of yaws being clinically resistent to repeated penicillin treatments is not surprising since evidence exists that strongly suggests that treponemes do have the potential to acquire resistence determinants. ${ }^{16}$ Plasmid DNA has been found in a strain of Treponema palliduim $^{17}$ and in an experimental setting treponemes do have the ability to acquire antibiotic resistance. Although such antibiotics as chloramphenicol, tetracycline, erthromycin and cephalosporins have all been shown to be efficacious for therapy for syphilis, there is no recent information concerning their efficacy in treatment of yaws. Since tetracyclines were used successfully in treatment of yaws in a limited clinical trial ${ }^{18}$ the positive response experienced with doxycycline treatment is not surprising. If with the repetition of the serological testing in several years there is a decrease in the titres with no reappearance of clinical lesions, doxycycline can be used as an alternative antibiotic for the treatment of yaws.

As the serological tests used in this study (RPR and FTA-Abs) are unable to distinguish yaws from other treponemal infections, it is possible that some of the infections labelled as latent yaws were due to Treponema palliduim. However, none of the cases gave a history of or had clinical evidence of syphilis, which, while not excluding syphilis, makes the diagnosis at an epidemiological level, less likely. In addition, it is probable that some seropositive individuals although they were effectively treated in 1988, still maintained residual antibody levels, not indicative of active disease.

The clinical lesions of yaws seen in all of the newly infected cases were of the classic type: frambesa form, papillomata which presented as single, multiple or generalised lesions al over the body. There were no cases of attenuated, atypical lesions which have been reported in areas where the prevalence has been reduced by control measures. ${ }^{19}$ Since, in the present study emphasis was put on the evidence of new or recurrent infections (such as primary and secondary papillomata) no mention was made of late yaws. The prevalence of late yaws (gangosa) was unchanged from the 1988 survey.

The general aim of any control programme is to eliminate infectious yaws. The specific intention is to stop or reduce transmission and therefore incidence by attacking the main source of infection, the secondary eruption. In the past, the majority of control programmes used against endemic yaws have been vertical. $^{20}$ These generally have been very costly, 
have had incomplete coverage, and have experienced poor community cooperation. Few programmes have been sustainable. These programmes have also failed to actively seek and treat yaws cases and contacts after mass treatment campaigns have terminated. ${ }^{21}$

Using the horizontal programme in which community-based health workers are involved in all aspects of the control program in Ecuador has yielded excellent results. Since a community-based health care system already existed and was involved in the control and monitoring of other tropical diseases, such as malaria, leprosy, onchocerciasis, and leishmaniasis in the yaws-endemic areas, educating and training these workers to include one more disease was not difficult. Education programmes were intensified to make the health leaders more aware of the disease, more skilled in its diagnosis and treatment, and in the management of patients and contacts. On the community level these leaders in turn were responsible: (1) to educate their respective communities about the disease and how it could be controlled; (2) to update all censuses and identify all clinical cases which would later be verified by the area supervisor; (3) to assist in sample taking for serology to detect latent infections; (4) to treat all indicated communities and individuals with penicillin; and (5) to maintain a constant surveillance and control of new clinical cases and their contacts. Community cooperation was excellent as each community were motivated to eliminate this disease which affects primarily their children. The health worker's aggressive surveillance to identify and treat all new clinical cases and contacts has been a major factor in maintaining the low prevalence of yaws in this focus.

This study has shown that by using a community based health care system, the deficiencies experienced with the vertical control programmes can be overcome. Community health care workers play a key role not only in the mass treatment campaigns but in their respective communities as they aggressively seek and contain yaws cases after mass treatment campaigns have reduced yaws prevalence to low levels. In this manner yaws can be controlled effectively and perhaps one day may be eradicated.

1 Naranjo MA. Pian en la provinca de Esmeraldas. Rev Ecua Med Cien Biol 1977;13:179-82.

2 Paltaw JD. Pian. In: Observaciones sobre Patologia Tropical. Ministerio de Gobierno, Quito, Ecuador, 1944:20-1

3 Santiana A. Pian. In: El Estudio de la Patologia del Oriente. Ministerio de la Comisión Sanitaria y Previsión Social, Quito, Ecuador, 1942:50-1.

4 Ministerio de la Salud Publica del Ecuador. Programa de Control y Vigiláncia Epidemiológica del Pian, Leishmaniasis y Hansen en la provincia de Esmeraldas. Dirección Nacional de Control y Vigiláncia Epidemiológica, 1983.

5 Guderian RH, Dávalos A. Pian en el Río Onzoles, Provincia de Esmeraldas. Med Ecuat 1985;2:17-20.

6 Guderian RH, Guevara A, Dávalos A. La presencia de gangosa en el Río Cayapas, Provincia de Esmeraldas. Rev Ecuat Hig Med Trop 1987;37:53-60

7 Guderian RH, Rumbea J, Calvopiña M, Cooper J. Studies on a focus of yaws in the Santiago Basin, province of Esmeraldas, Ecuador. Trop Geograph Med 1991;43 142-7.

8 Vorst FA. Clinical diagnosis and changing manifestations of treponemal infections. Rev Inf Dis 1985;7(suppl 2): s327-31.

9 Larsen LA, D'Costa JF. Laboratory tests and serological surveillance for yaws and other diseases and conditions. Southeastern Asian $\mathcal{F}$ Trop Med Publ Hlth 1986;17(suppl): s70-7.

10 World Health Organization. Treponemal Infections. Tech Report Ser 674, 1982:50-1.

11 Tharmaphornpilas P, Srivanichakorn S, Phraesrisakul N. Recurrence of yaws outbreak in Thailand. 1994 Southeast Asian 7 Trop Med Publ Hlth 1994;25:152-6.

12 Edorh AA, Siamevi EK, Adanlete FA, et al. Resurgence of endemic yaws in Togo. Cause and eradication approach Bull Soc Pathol Exot 1994;87:17-8.

13 Herve V, Kassa Kelembjo E, Normand P, Georges A Mathiot C, Martin P. Resurgence of yaws in Central African Republic. Role of the Pygmy population as a reservoir of the virus. Bull Soc Pathol Exot 1992;85:342-6.

14 Engelkens HJ, Stolz E. A small yaws survey on the island of Sumatra, Indonesia. Acta Leiden 1992;60:19-29.

15 Meheus A, Antal GM. The endemic treponematoses: not yet eradicated. World Health Stat $O 1992 ; 45: 228-37$.

16 Stapleton JT, Stamm LV, Bassford PJ. Potential for development of antibiotic resistance in pathogenic treponemes. Rev Inf Dis 1985;7(suppl):s 314-7.

17 Norgard MV, Miller JN. Plasmid DNA in Treponema palliduim (Nichols): potential for antibiotic resistance by syphilis bacteria. Science 1981;213:553-5.

8 Loughlin EH, Joseph A, Schoeffer K. Aureomycin in the treatment of yaws. Am F Trop Med Hyg 1951;31:20-5.

9 Niemel PLA, Sadal S, Van der Sluis JJ. Yaws in Suriname. Rev Inf Dis 1985;7(suppl 2):s273-5.

20 Wilcox RR. Mass treatment campaigns against the endemic treponematoses. Rev Inf Dis 1985;7(suppl 2):s278-83.

21 Hopkins DR. After smallpox eradication: yaws? Am $\mathcal{F}$ Trop Med Hyg 1976;25:860-5. 